\title{
Clinical significance of anti-filaggrin antibody recognizing uncitrullinated filaggrin in rheumatoid arthritis
}

\author{
Kyung-Ho Choi ${ }^{1 *}$, Eun Bong Lee ${ }^{2 *}$, \\ Chang Dal Yoo ${ }^{2}$, Han Joo Baek, \\ Seong Wook Kang ${ }^{2}$, Ki Chul Shin ${ }^{2}$, \\ Yun Jong $\mathrm{Lee}^{2}$, Hyun Ah Kim${ }^{2}$, \\ Ju-Hong Jeon ${ }^{1}$, Chai-Wan Kim ${ }^{1}$, \\ Dong-Myung Shin ${ }^{1}$, In-Gyu Kim ${ }^{1,3}$ \\ and Yeong Wook Song ${ }^{2}$
}

\author{
${ }^{1}$ Department of Biochemistry and Molecular Biology \\ Biology/Aging and Apoptosis Research Center (AARC) \\ ${ }^{2}$ Department of Internal Medicine and Clinical Reasearch Institute \\ Seoul National University College of Medicine \\ Seoul 110-799, Korea \\ ${ }^{3}$ Corresponding author: Tel, 82-2-740-8248; \\ Fax, 82-2-744-4534; E-mail, igkim@plaza.snu.ac.kr \\ *These authors contributed equally to this work.
}

Accepted 29 September 2005

Abbreviations: $A D L$, activity of daily living; AFA, anti-filaggrin antibody; AKA, anti-keratin antibody; ANA, anti-nuclear antibody; APF, anti-perinuclear factor; AS, ankylosing spondylitis; CRP, C-reactive protein; ESR, erythrocyte sedimentation ratio; OA, osteoarthritis; $R A$, rheumatoid arthritis; RF, rheumatoid factor; SLE, systemic lupus erythematosus

\footnotetext{
Abstract

Filaggrin is expressed in the cornified layer of epidermis and known to be one of the antigenic targets in rheumatoid arthritis. Although the citrulline residue in filaggrin is thought to be an antigenic determinant recognized by autoantibodies, the diagnostic sensitivity of synthetic citrullinated peptide is variable. To investigate the implication of anti-filaggrin antibodies recognizing uncitrullinated filaggrin in rheumatoid arthritis, we assayed antibody titers using unmodified recombinant filaggrin in the sera from 73 patients with rheumatoid arthritis, 150 patients with other connective tissue diseases and 70 normal controls. We also performed the correlation analysis between antibody titers and the clinical variables in patients with rheumatoid arthritis. Titers of IgG anti-filaggrin antibodies were significantly higher in rheumatoid arthritis patients compared to normal controls $(P=0.02)$, but not in
}

patients with osteoarthritis, ankylosing spondylitis or systemic lupus erythematosus. IgG anti-filaggrin antibodies were more frequently found in patients with rheumatoid arthritis compared to normal controls $(12.3 \%$ vs $1.4 \%$ respectively, $P=0.04)$. An anti-filaggrin antibody titer was correlated with visual analogue scale of pain, tender joint count, Ritchie articular index or C-reactive protein, but not with anti-nuclear antibody or rheumatoid factor. These results suggest that anti-filaggrin antibody recognizes the uncitrullinated filaggrin as an antigen and its titer correlates with clinical parameters, explain ing the variable sensitivity of anti-filaggrin antibody test.

Keywords: autoimmune; cyclin citrullinated peptide; diseases; filaggrin; immunoenzyme techniques; rheumatoid arthritis

\section{Introduction}

Rheumatoid arthritis (RA) is a chronic inflammatory joint disease affecting around $1 \%$ of the general population (Kellgren, 1996). Although rheumatoid factor (RF) is helpful in diagnosis of RA (Arnett et al., 1998), it can be found in patients with other rheumatic diseases or even healthy persons and is negative in $20-30 \%$ of RA patients (Schrohenloher et al., 1997).

Various serologic markers were suggested to overcome the low specificity of the RF, including Sa, kalpastatin, antikeratin antibody (AKA) and antiperinuclear factor (APF) (Menard et al., 1998). The AKA and APF, which are the antibodies against the cornified epithelium of rat esophagus and human buccal mucosa respectively, are known to be specific for RA (Nienhuis et al., 1964; Young et al., 1979). The antigen targets of both antibodies were suggested to be the same protein which is filaggrin in the human epidermis (Hoet et al., 1991; Simon et al., 1993; Sebbag et al., 1995). Filaggrin is synthesized in the stratum granulosum as a large repeated (10-12 repeat of filaggrin monomers) and heavily phosphorylated precursor, profilaggrin, which is stored in the keratohyaline granules. After dephosphorylation and proteolysis, filaggrin monomer is released from profilaggrin and modified by peptidylarginine deiminase which converts the arginine resi- 
dues found in filaggrin to the citrulline. Modified filaggrin is thought to be interacted and aggregated with the keratin intermediate filaments in keratinocytes, facilitating and guiding their alignment (Berthelot et al., 1995).

Since the molecular identity of target antigen was elucidated, several approaches have been made to detect antifilaggrin antibody (AFA) using human filaggrin. Immunoblot tests using the filaggrin extract from human epidermis showed variable sensitivity ranging from $12.0-67.9 \%$, with the specificity of 92.0-95.4\% (Vincent et al., 1998; Slack et al., 1998). ELISA using filaggrin purified from human epidermis detected IgG AFA in $47 \%$ of RA patients (Palosuo et al., 1998). Recently, ELISA using a cyclic citrullinated synthetic peptide derived from the sequence of human filaggrin showed a higher specificity than other methods (Schellekens et al., 2000; Girelli et al., 2004). However, the heterogeneity of extracted filaggrin or synthesized peptide sequence makes it difficult to get consistent results, and thus to evaluate the correlations between the presence of autoantibody and clinical data related to RA activity. In this study, we report that ELISA using unmodified recombinant filaggrin showed a $12.3 \%$ diagnostic sensitivity at a specificity of $95 \%$ which was correlated with visual analogue scale of pain, tender joint count, Ritchie articular index or C-reactive protein in RA patients.

\section{Materials and Methods}

\section{Serum samples}

Serum samples were obtained from 73 patients diagnosed as RA according to the revised criteria by American Rheumatism Association (Arnett et al., 1998), 70 healthy controls and 150 patients with other connective tissue diseases including osteoarthritis (OA), ankylosing spondylitis (AS) and systemic lupus erythematosus (SLE) at Rheumatology Clinic, Seoul National University Hospital. Serum samples were stored at $-70^{\circ} \mathrm{C}$ until assayed.

\section{Expression and purification of the recombinant filaggrin monomer}

Human filaggrin monomer cDNA was obtained by PCR amplification of the partial CDNA clone of profilaggrin ( $\lambda$ HF11 provided by Dr. P. Steinert; Gan et al., 1990). PCR was performed with sense primer (FilP) 5'-CATATGTTCCTCTACCAGGTGAGC-3' and antisense primer (FilN) 5'-TCTGGACATTCAGGATCTTAACTCGAG-3'. The amplified product was verified by sequencing (Sequenase kit; USB, Cleveland, $\mathrm{OH}$ ) and subcloned into the corresponding sites of
pET15b expression vector after digestion with Nde I and Xho I. The recombinant plasmid was introduced into the expression host, BL21 (DE3).

The recombinant human filaggrin was prepared by pET bacterial expression system (Novagen, Madison, WI). Induction and purification of the recombinant protein was performed according to manufacturer's instructions. Briefly, transformed cells were cultured in LB medium plus $100 \mu \mathrm{g} / \mathrm{ml}$ ampicillin at $37^{\circ} \mathrm{C}$. Filaggrin production was induced in the presence of $1 \mathrm{mM}$ isopropyl $\beta$-o-thiogalactopyranoside (IPTG). The washed cells from 1-liter culture were resuspended in $10 \mathrm{ml}$ of binding buffer $(20 \mathrm{mM}$ Tris-Cl, $0.5 \mathrm{M} \mathrm{NaCl}, 5 \mathrm{mM}$ imidazole, $\mathrm{pH}$ 7.9) and lysed by sonication. The suspension was centrifuged at $39,000 \times g$ for 20 minutes at $4^{\circ} \mathrm{C}$. The supernatant was filtered through a $0.45 \mu \mathrm{m}$ membrane and loaded on $6 \mathrm{ml}$ HisBind metal chelation resin (Novagen, Madison, WI) pre-charged with $50 \mathrm{mM}$ NiSO4 and equilibrated with binding buffer. The column was washed with $60 \mathrm{ml}$ binding buffer and then with $30 \mathrm{ml}$ each of washing buffer containing 60 $\mathrm{mM}$ or $100 \mathrm{mM}$ imidazole $(20 \mathrm{mM}$ Tris-Cl, $0.5 \mathrm{M}$ $\mathrm{NaCl}, 60 \mathrm{mM}$ or $100 \mathrm{mM}$ imidazole, $\mathrm{pH} 7.9$ ). The recombinant protein was eluted with $30 \mathrm{ml}$ elution buffer $(20 \mathrm{mM}$ Tris- $\mathrm{Cl}, 0.5 \mathrm{M} \mathrm{NaCl}, 1 \mathrm{M}$ imidazole, $\mathrm{pH}$ 7.9). The eluate was concentrated by ultrafiltration (Ultrfree-15: Millipore, Bedford, MA).

For the immunoblot analysis, protein samples were electrophoresed under denaturing condition, and transferred to a nitrocellulose membrane. The membrane was blocked with $5 \%$ skim milk in Tris-buffered saline (TBS) for an hour and then incubated with mouse antifilaggrin monoclonal antibody (Biomedical Technologies, Stoughton, MA) for an hour. Peroxidase-labelled anti-mouse lg antibody (Dako, Glostrup, Denmark) was used as a secondary probe and visualization was performed with enhanced chemiluminescence (Amersham, Piscataway, NJ).

\section{Immunoblotting with human sera}

One microgram of recombinant filaggrin was run on SDS-polyacrylamide gel and transferred to a nitrocellulose membrane. The membrane was cut into strips and blocked with $5 \%$ skim milk in TBS. The strips were incubated with the patient sera diluted 1:100 for an hour at room temperature. After washing several times, the strips were treated with peroxidase-labelled anti-human IgG antibody (Dako, Glostrup, Denmark) for an hour at room temperature. The color reaction was developed by 3,3-diaminobenzidine substrate (Sigma, St. Louis, MO).

\section{ELISA}

The recombinant filaggrin $(1 \mu \mathrm{g} /$ well) was coated on 
a 96-well immunoassay plate (Maxisorp; Nunc, Rockside, Denmark) at $4{ }^{\circ} \mathrm{C}$, overnight. After washing with phosphate buffered saline-0.05\% Tween-20 (PBST), blocking was done with $1 \%$ bovine serum albumin in PBS at room temperature for $2 \mathrm{~h}$. Then, the coated plate was incubated with $100 \mu \mathrm{l} /$ well of 1:100 diluted sera for $2 \mathrm{~h}$. After washing 5 times, 100 $\mu l$ of alkaline phosphatase-conjugated goat antihuman IgG $(1: 4,000$, American Qualex, La Mirada, CA) or IgM $(1: 4,000$, Southern Biotechnology, Birmingham, $A L$ ) antibody was added to each well. After incubation for $2 \mathrm{~h}$, the plate was washed 6 times and $100 \mu \mathrm{l}$ of $1 \mathrm{mg} / \mathrm{ml} \rho$-nitrophenyl phosphate in dienthanolamine- $\mathrm{MgCl}_{2}$ was added to each well. The reaction was stopped by adding $50 \mu \mathrm{l}$ of 3 $\mathrm{M} \mathrm{NaOH} /$ well and optical density (OD) was read at a wavelength of $405 \mathrm{~nm}$. OD measured on uncoated well was subtracted. The cut-off value was defined as 3 Standard Deviation (SD) above the mean of normal controls. Arbitrary units (a.u.) were obtained according to the formula; 1 a.u. = patient OD value/ cut-off value. All serum samples were assayed in duplicate.

\section{Clinical evaluation in patients with RA}

The following features were assessed in 73 patients with RA; functional class (Hochberg et al., 1991), anatomical stage (Steinbocker et al., 1949), duration of morning stiffness, grip strength (Lee et al., 1974), pain (visual analogue scale, $10 \mathrm{~cm}$ ), activity of daily living (ADL) (Callahan et al., 1987), 68-joint count for tenderness, 66-joint count for swelling (Felson et al., 1993), Ritchie articular index (Richie et al., 1968), complete blood count, Westergren erythrocyte sedimentation rate (ESR), C-reactive protein (CRP), titer of RF and antinuclear antibody (ANA). Joint X-ray survey was done for both shoulders, hands, knees, feet, cervical spine, lumbosacral spine and pelvis in all patients.

\section{Statistical analysis}

The data were analyzed using SAS statistical software (version 6.03). Student $t$-test was used for comparison of continuous variables. Chi-square test was applied for analysis of nominal variables. Correlation coefficients were measured between the titer of AFA and the clinical variables; Spearman correlation coefficients for functional class or anatomical stage and Pearson correlation coefficients for other variables. $P$-value less than 0.05 was considered significant.

\section{Results}

\section{Purification of recombinant filaggrin}

The protein sequences of monomeric filaggrin are shown in Figure 1. The recombinant filaggrin, tagged with histidine hexamer at the $\mathrm{N}$-terminal end, was expressed mainly in the soluble form in host $E$. coli under the control of IPTG. The protein purified by $\mathrm{Ni}^{2+}$ column chromatography was pure enough to appear as a single band with $40 \mathrm{kD}$ in size on SDS-PAGE, and the immunoblot revealed it to be a filaggrin (Figure 2).

\section{Detection of AFA in human sera}

For the detection and quantitation of AFA in patient sera, we designed an ELISA method using the purified recombinant filaggrin as a coating antigen. Sera from 70 normal controls, 73 RA patients and 150 patients with other connective tissue diseases (OA 50, AS 50, SLE 50) were tested at 1:100

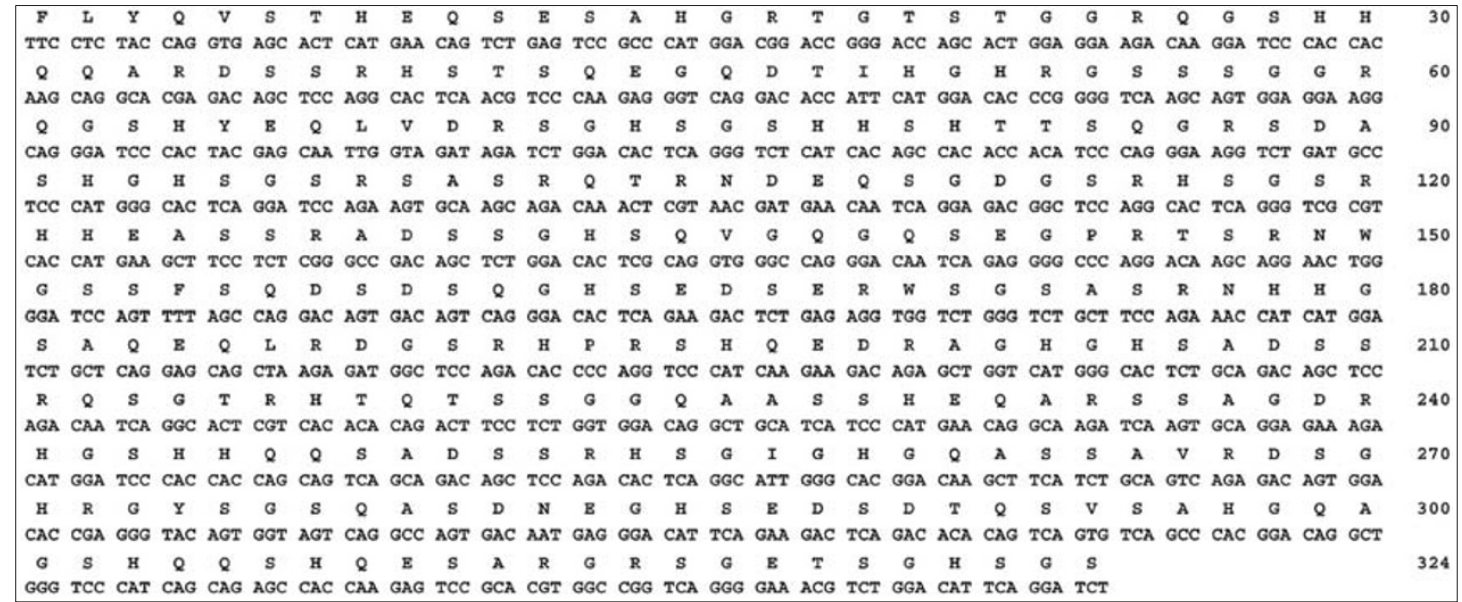

Figure 1. The amino acids sequence of human recombinant filaggrin used in this study. 
dilution. As both APF and AKA were mainly IgG isotype, IgG AFA was tested first. The average AFA titer of RA patients was significantly higher than that of normal controls (mean \pm SEM; $0.417 \pm 0.100$ a.u. versus $0.179 \pm 0.028$ a.u., $P=0.02$ ), whereas other disease groups showed the similar AFA titer (Table 1, Figure $3 A$ ). In contrast, IgM AFA titer showed no difference between RA patients and normal controls $(0.279 \pm 0.029$ a.u. versus $0.209 \pm 0.026$ a.u., $P=$ 0.08) (Figure 3B). When the cut-off value was

A

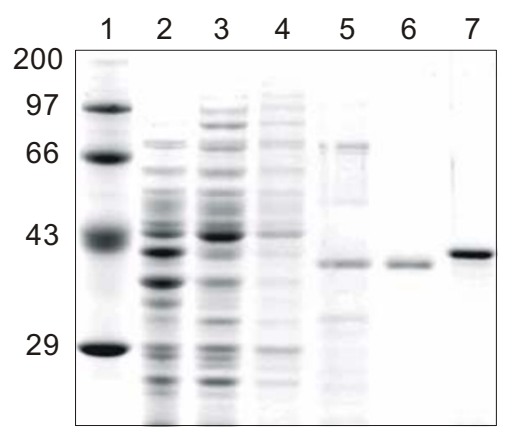

B

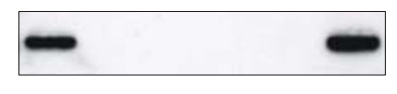

Figure 2. Purification of the recombinant filaggrin. The lysed cell extract was loaded on $\mathrm{Ni}^{2+}$ column. During the washing, imidazole concentration increased up to $100 \mathrm{mM}$ in a step gradient manner. The $40 \mathrm{kD}$ target protein was eluted at $1 \mathrm{M}$ imidazole and electrophoresed on a $8 \%$ SDS-polyacrylamide gel. The fractionated bands were stained with Coomassie blue (A) or analyzed by immunoblot with mouse anti-human filaggrin antibody (B). 1, molecular weight marker $(k D) ; 2$, the lysed cell extract; 3, the flow-through; 4, $5 \mathrm{mM}$ imidazole; 5, $60 \mathrm{mM}$ imidazole; 6 , $100 \mathrm{mM}$ imidazole; 7, $1 \mathrm{M}$ imidazole.

A

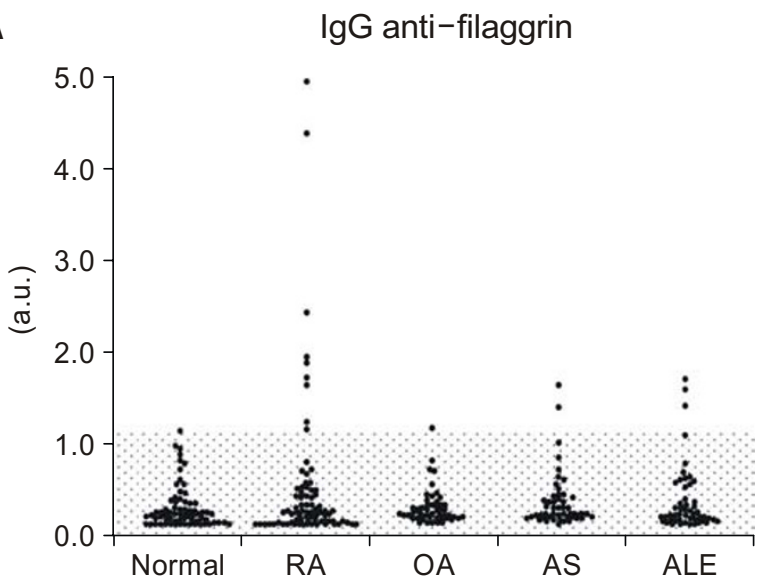

defined as $3 \mathrm{SD}$ above the mean of normal controls, 9 from 73 RA sera $(12.3 \%)$ were positive for $\lg$ G AFA, whereas 1 from 70 normal sera (1.4\%), 1 from 50 OA sera $(2 \%), 2$ from 50 AS sera $(4 \%)$, and 4 from 50 SLE sera $(8 \%)$ were positive. The sensitivity and specificity of the IgG AFA test in RA patients were calculated as $12.3 \%, 96.0 \%$ respectively. Immunoblot with RA sera showed that AFA in human sera binds to the recombinant filaggrin (Figure 4).

\section{AFA titer and clinical features of RA patients}

To evaluate the clinical significance of AFA positivity and titer, we categorized the clinical features of RA patients and examined the correlation with AFA titer. The baseline clinical characteristics of 73 RA patients were as Table 2. At the study entry, 46 patients were receiving at least one of the disease modifying anti-rheumatic drugs (hydroxychloroquine 34 , methotrexate 30 , azathioprine 6 , sulfasalazine 5 , bucil-

Table 1. IgG AFA titer in RA and other connective tissue diseases. The IgG AFA titer of RA patients was significantly higher than that of normal controls.

\begin{tabular}{lcc}
\hline \multicolumn{1}{c}{ Disease } & $\begin{array}{l}\text { IgG AFA } \\
\text { (a.u., mean } \pm \text { SEM) }\end{array}$ & $P$-value \\
\hline Rheumatoid arthritis $(n=73)$ & $0.417 \pm 0.100$ & 0.03 \\
Osteoarthritis $(n=50)$ & $0.189 \pm 0.028$ & 0.80 \\
Ankylosing spondylitis $(n=50)$ & $0.250 \pm 0.043$ & 0.15 \\
Systemic lupus & $0.266 \pm 0.053$ & 0.12 \\
erythematosus $(n=50)$ & $0.179 \pm 0.028$ & \\
Normal controls $(n=70)$ & \\
\hline
\end{tabular}

B

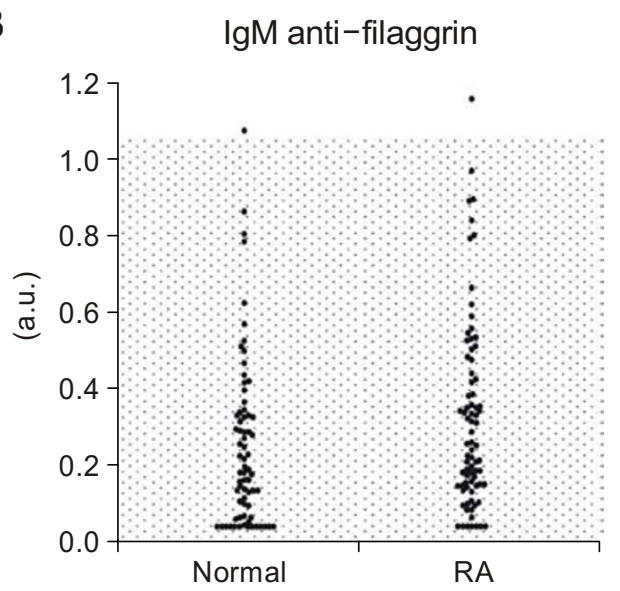

Figure 3. IgG AFA in connective tissue diseases (A) and IgM AFA (B) in RA. Shaded area represents the range of optical density value lower than the cut-off value of 1 arbitrary unit (a.u.). The cut-off value was chosen as 3 SD above the mean of normal control optical density values. IgG antifilaggrin titer was significantly higher in RA patients compared with that of noraml controls $(P=0.02)$. There was no significant difference of IgM AFA titer between RA patients and normal controls. 


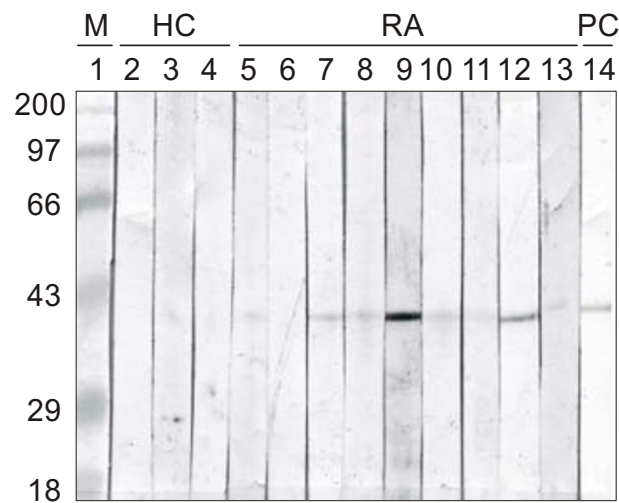

Figure 4. Reactivity of RA sera to the recombinant filaggrin in immunoblot. After the electrophoretic separation and transfer of $1 \mu \mathrm{g}$ recombinant filaggrin, 3 healthy control sera (lane 2-4), 9 RA sera (lane $5-13)$ were tested at 1:100 dilution. Lane 14 was reacted with mouse anti-human filaggrin monoclonal antibody as a positive control. M, marker; $\mathrm{HC}$, healthy control; RA, rheumatoid arthritis; PC, positive control.

Table 2. Baseline clinical chracteristics of patients with RA.

\begin{tabular}{lc}
\hline \multicolumn{1}{c}{ Clinical charateristics } & $n=73$ \\
\hline Female (\%) & $61(83.6 \%)$ \\
Age (years, mean \pm SD) & $49.6 \pm 12.6$ \\
Duration (months, mean \pm SD) & $113.3 \pm 114.1$ \\
Rheumatoid factor (\%) & $52(71 \%)$ \\
DMARDs (\%)* & $46(63 \%)$ \\
\hline
\end{tabular}

*Disease modifiying anti-rheumatic drugs.

lamine 2). Low dose prednisolone was administered in 27 patients.

IgG AFA was positive in 9 (12.3\%) out of 73 RA patients. With respect to the RF, eight patients showed positive AFA (15.4\%) in 52 RF positive patients, compared with only one $(4.8 \%)$ in $21 \mathrm{RF}$ negative patients $(P=0.09)$. All patients with positive AFA were suffering from RA longer than 12 months. AFA was positive in $7(13.5 \%)$ out of 52 patients with one or more marginal erosions in joint X-rays, while it was positive in $2(10 \%)$ out of 20 patients without erosion $(P=0.43)$.

When correlation analysis was performed between AFA titers and clinical variables in AFA positive RA patients, the severity of pain measured by visual analogue scale $(r=0.73, P=0.03)$, tender joint count $(r=0.76, P=0.02)$, Ritchie articular index $(r=$ $0.89, P=0.001), \operatorname{CRP}(r=0.82, P=0.01)$ and platelet count $(r=-0.75, P=0.03)$ showed significant correlation (Table 3 ).
Table 3. Correlation between AFA titer and clinical variables in AFA positive RA patients.

\begin{tabular}{lrl}
\hline \multicolumn{1}{c}{ Variables } & $r$ & $P$ \\
\hline Functional class & 0.00 & 1.00 \\
Anatomical stage & 0.25 & 0.52 \\
Morning stiffness & -0.19 & 0.62 \\
Grip Strength (right) & -0.27 & 0.48 \\
Grip Strength (left) & -0.37 & 0.32 \\
Pain (VAS) & 0.73 & 0.03 \\
ADL & 0.56 & 0.12 \\
Tender joint count & 0.76 & 0.02 \\
Swollen joint count & 0.31 & 0.42 \\
Ritchie index & 0.89 & 0.001 \\
C-reactive protein & 0.82 & 0.01 \\
White blood cell & 0.43 & 0.28 \\
Platelet & -0.75 & 0.03 \\
Westergren ESR & 0.52 & 0.18 \\
RF titer & 0.08 & 0.84 \\
\hline
\end{tabular}

$A D L$, activity of daily living; ESR, erythrocyte sedimentation rate; RF, rheumatoid factor; VAS, visual analogue scale

\section{Discussion}

AFA is the autoantibody to filaggrin in human epidermis and detected in the RA patients by immunoblot analysis and ELISA using human epidermal extracts or synthetic citrullinated peptide as an antigen (Palosuo et al., 1998; Vincent et al., 1998; Schellekens et al., 2000). Although the specificity of the tests was high $(92.0-95.4 \%)$, the sensitivity of the tests was variable $(12.0-67.9 \%)$ probably due to the difference in source of filaggrin extracted or in sequences of citrullinated peptide from various providers.

Human filaggrin consists of a heterogeneous population of monomers of different sequences and charges. Furthermore, human filaggrin shows considerable polymorphic sequence variations between individuals (McKinley-Grant et al., 1989; Gan et al., 1990). In addition, the post-translationally modified arginine residue in filaggrin monomer is thought to be an antigenic determinant recognized by AFA (Schellekens et al., 1998). However, the number and location of modified arginine in filaggrin repeats have not been determined. Our study was conducted to test whether AFA could react with unmodified human filaggrin and whether the presence of this antibody in RA patients correlates with the clinical and laboratory profiles.

To guarantee the antigenic homogeneity of recombinant filaggrin which is not modified, we used bac- 
terial expression system. Because proteolytic cleavage site of filaggrin precursor protein has not been exactly determined yet, we designed the filaggrin monomer for expression as suggested previously (Gan et al., 1990). The filaggrin monomer includes the linker and proposed filaggrin sequences. With our ELISA system, the sensitivity of AFA in RA patients was $12.3 \%$ with the specificity of $95 \%$. High specificity of the test reconfirmed the previous reports (Vincent et al., 2005) and suggested that the AFA test could be used to differentiate the RA from other inflammatory arthritis. The low positivity rate can be explained as follows. First, there is heterogeneity of the filaggrin monomers which show the sequence variability in $30-40 \%$ of amino acids (Gan et al., 1990). Second, recombinant filaggrin might not have the appropriate tertiary structure which is needed for the antibody binding. Third, citrullination may explain two third of the AFA-positive sera (Schellenkens et al., 1998; Kroot et al., 2000). Fourth, the prevalence of the AFA in Korean patient group may be low compared with those of other ethnic groups. The reported prevalence of AFA was variable (12.0-67.9\%) and in case of AKA, the Greek patients with RA had low positivity $(16 \%)$ in spite of consistently high positivity $(36-69 \%)$ in other ethnic groups.

AKA and APF could be positive at subclinical stage of RA (Paimela et al.,1992) and IgG AKA was found in $38 \%$ of RA patients whose disease duration is less than one year (Aho et al., 1993). AKA and APF were suggested to be early diagnostic markers of RA. However, unlike AKA or APF, we could not detect AFA among 8 patients in whom the duration of the disease was less than $1 \mathrm{yr}$. AKA and APF were reported to show higher positivity rate in patients with destructive RA (Westgeest et al., 1987; Kurki et al., 1997). However, there was no difference in AFA positivity between the patients with and without marginal erosion in our patient group. It was reported that the frequency of RF is increased in AKA or APF positive patients (Paimela et al., 1992). In this study, the frequency of RF positivity tended to be higher in AFA positive patients compared with AFA negative patients ( $89 \%$ versus $67 \%, P=0.18$ ).

The association of AFA with the clinical and laboratory profiles in RA patients has not been well described. Recently, only one study reports a correlation between the presence of anti-citrullinated peptide antibodies and the functional disability (Bas et al., 2003). We found positive correlation between AFA titer and several clinical features including pain in visual analogue scale, tender joint count, Ritchie articular index and CRP. Platelet count was negatively correlated with AFA titer. The clinical significance of negative correlation between platelet count and AFA titer remains to be explained.

In conclusion, we showed that AFA recognizes the recombinant filaggrin monomer which is not citrullinated as an antigen, explaining the variable sensitivity of AFA test. Antibody titer was significantly increased in RA patients and showed correlation with pain in visual analogue scale, tender joints count, Ritchie articular index and CRP.

\section{Acknowledgement}

This work was supported by Seoul National University Hospital (03-1997-010-1), Ministry of Health and Welfare (HMP-97-B-2-0011) and Korea Science and Engineering Foundation (KOSEF; R11-2002097-07003-0 and R01-2005-000-10364-0) through the Center for Aging and Apoptosis Research. J.H.J., C.W.K. and D.M.S. were supported by the graduate program of BK21 project, administrated by the Ministry of Education and Human Resources Development.

\section{References}

Aho K, von Essen R, Kurki P, Palosuo T, Helliövaara M. Antikeratin antibody and antiperinuclear factor as markers for subclinical rheumatoid disease process. J Rheumatol 1993; 20:1278-81

Arnett FC, Edworthy SM, Bloch DA, McShane DJ, Fries JF, Cooper NS. The American Rheumatism Association 1987 revised criteria for the classification of rheumatoid arthritis. Arthritis Rheum 1998;31:315-24

Bas S, Genevay S, Meyer O, Gabay C. Anti-cyclic citrullinated peptide antibodies, IgM and IgA rheumatoid factors in the diagnosis and prognosis of rheumatoid arthritis. Rheumatology 2003;42:677-80

Berthelot JM, Maugars Y, Prost A, Youinou P. Rheumatoid arthritis and filaggrin, a review. Rev Rhum 1995;62:127-38

Callahan LF, Brooks RH, Summey JA, Pincus T. Quantitative pain assessment for routine care of rheumatoid arthritis patients, using a pain scale based on activities of daily living and a visual analog pain scale. Arthritis Rheum 1987;30: 630-6

Felson DT, Anderson JJ, Boers M, Bombardier C, Chernoff $M$, Fried B. The American College of Rheumatology preliminary core set of disease activity measures for rheumatoid arthritis clinical trials. Arthritis Rheum 1993;36:729-40

Gan SQ, McBride W, Idler WW, Markova N, Steinert M. Organization, structure, and polymorphisms of the human profilaggrin gene. Biochem 1990;29:9432-40

Girelli F, Foschi FG, Bedeschi E, Calderoni V, Stefanini GF, Martinelli MG. Is Anti Cyclic citrullinated peptide a useful laboratory test for the diagnosis of rheumatoid arthritis? Allergy Immunol 2004;36:127-30

Hochberg MC, Chang RW, Dwosh I, Lindsey S, Pincus T, 
Wolfe F. The American College of Rheumatology 1991 revised criteria for the classification of global functional status in rheumatoid arthritis. Arthritis Rheum 1992;35: 498-502

Hoet RM, Boerhooms AM, Arends M, Ruiter DJ, van Venrooij WJ. Antiperinuclear factor, a marker autoantibody for rheumatoid arthritis: colocalization of the perinuclear factor and profilaggrin. Ann Rheum Dis 1991;50:611-8

Kellgren JH. Epidemiology of rheumatoid arthritis. Arthritis Rheum 1996;9:658-74

Kroot EJA, de Jong BAW, van Leeuwen MA, Swinkels $H$, van den Hoogen FHJ, van't Hof M. The prognostic value of anti-cyclic citrullinated peptide antibody in patients with recent onset rheumatoid arthritis. Arthritis Rheum 2000;43: 1831-5

Kurki P, von Essen R, Kaarela K, Isomäki H, Palosuo T, Aho $\mathrm{K}$. Antibody to stratum corneum (anti-keratin antibody) and antiperinuclear factor: markers for progressive rheumatoid arthritis. Scand J Rheumatol 1997;26:346-9

Lee P, Baxter A, Dick WC, Webb J. An assessment of grip strength measurement in rheumatoid arthritis. Scand $\mathrm{J}$ Rheumatol 1974;3:17-23

McKinley-Grant LJ, Idler WW, Bernstein IA, Parry DA, Cannizzaro L, Croce CM. Characterization of a cDNA clone encoding human filaggrin and localization of the gene to chromosome region 1q21. Proc Natl Acad Sci 1989;86: 4848-52

Ménard HA, El Amine M, Després N. Rheumatoid arthritis associated autoimmune systems. J Rheumatol 1998;25: 835-7

Nienhuis RLF, Mandema E, Smids C. A new serum factor in patients with rheumatoid arthritis, the antiperinuclear factor. Ann Rheum Dis 1964;23:302-5

Paimela L, Gripenber M, Kurki P, Leirisalo-Repo M. Antikeratin antibodies: diagnostic and prognostic markers for early rheumatoid arthritis. Ann Rheum Dis 1992;51:743-6

Palosuo T, Lukka M, Alenius H, Kalkkinen N, Aho K, Kurki P. Purification of filaggrin from human epidermis and measurement of antifilaggrin autoantibodies in sera from patients with rheumatoid arthritis by an enzyme-linked immunosorbent assay. Int Arch Allergy Immunol 1998;115:294-302

Ritchie DM, Boyle JA, Mclnnes JM, Jasani MK, Dalakos TG, Grieveson P. Clinical studies with articular index for the as- sessment of joint tenderness in patients with rheumatoid arthritis. Q J Med 1968;37:393-406

Schellenkens GA, de Jong BAW, van den Hoogen FHJ, van de Putte LBA. Citrulline is an essential constituent of antigenic determinants recognized by rheumatoid arthritis-specific autoantibodies. J Clin Invest 1998;101:273-81

Schellekens GA, Visser $\mathrm{H}$, de Jong BA, Van den Hoogen FH, Hazes JM, Breedveld FC, Van Venrooij WJ. The diagnostic properties of rheumatoid arthritis antibodies recognizing a cyclic citrullinated peptide. Arthritis Rheum 2000;43:155-63

Schrohenloher RE, Bridges SL, Koopman WJ. Rheumatoid factor. In Arthritis and allied conditions, a textbook of rheumatology (Koopman WJ eds), 1997, 1109-30, Williams \& Wilkins, Baltimore

Sebbag M, Simon M, Vincent C, Masson-Bessiére C, Girbal $\mathrm{E}$, Durieux JJ. The antiperinuclear factor and the so-called antikeratin antibodies are the same rheumatoid arthritisspecific autoantibodies. J Clin Invest 1995;95:2672-9

Simon M, Girbal E, Sebbag M, Gomès-Daudrix V, Vincent C, Salama G. The cytokeratin filament-aggregating protein filaggrin is the target of the so-called "anti-keratin antibodies", autoantibodies specific for rheumatoid arthritis. J Clin Invest 1993;92:1387-93

Slack SH, Mannik M, Dale BA. Diagnostic value of antibodies to filaggrin in rheumatoid arthritis. J Rheumatol 1998; 25:847-51

Steinbocker O, Traeger $\mathrm{CH}$, Batterman RC. Therapeutic criteria in rheumatoid arthritis. JAMA 1949;140:659-62

Vincent C, Simon M, Sebbag M, Girbal-Neuhauser E, Durieux J, Cantagrel A. Immunoblotting detection of autoantibodies to human epidermis filaggrin: a new diagnostic test for rheumatoid arthritis. J Rheumatol 1998;25:838-46

Vincent C, Nogueira L, Clavel C, Sebbag M, Serre G. Autoantibodies to citrullinated proteins: ACPA. Autoimmunity 2005;38:17-24

Westgeest AAA, Boerbooms AMT, Jongmans M, Vandenbroucke JP, Vierwinden G, van de Putte LBA. Antiperinuclear factor: indicator of more severe disease in seronegative rheumatoid arthritis. J Rheumatol 1987;14:893-7

Young BJJ, Mallya RK, Leslie RDG, Clark CJM, Hamblin TJ. Antikeratin antibodies in rheumatoid arthritis. BMJ 1979;2: 97-9 